\title{
A PESQUISA EM EDUCAÇÃO E O CAMPO DA FORMAÇÃO DE EDUCADORES: DIÁLOGOS COM MARLI ANDRÉ
}

\author{
Bernardete A. Gatti \\ Fundação Carlos Chagas - FCC \\ São Paulo - São Paulo - Brasil \\ gattibe@gmail.com \\ ORCID: https://orcid.org/0000-0002-9297-726X
}

RESUMO: No artigo são tratadas questões conceituais sobre aspectos da delimitação de campo de investigação científica e também questões relativas à pesquisa em formação de educadores. Esses temas foram objeto de intensas trocas com Marli André durante nossas vivências acadêmicas e parcerias em pesquisas. São tratados aspectos relativos à validade e consistência da produção científica, discutindo a variedade de possibilidades advindas com o emprego dos métodos qualitativos na pesquisa em educação e sobre a formação de professores, como também as preocupações sociais e educacionais suscitadas pela maior aproximação pesquisador-pesquisado, pesquisador-contexto.

PALAVRAS-CHAVE: Pesquisa em Educação; Pesquisa Qualitativa; Campo de pesquisa; Ética.

\section{RESEARCH IN EDUCATION AND THE FIELD OF TEACHER TRAINING: DIALOGUES WITH MARLI ANDRÉ}

ABSTRACT: The article deals with conceptual questions about aspects of the delimitation of the field of scientific investigation, as well as questions related to research in the formation of educators. These themes were the object of intense exchanges with Marli André during our academic experiences and research partnerships. Aspects related to the validity and consistency of scientific production are discussed, discussing the variety of possibilities arising from the use of qualitative methods in research in education and on teacher training, as well as the social and educational concerns raised by a closer researcher-researched and researcher-context approach.

KEYWORDS: Education Research; Qualitative research; Research field; Ethic. 


\section{INVESTIGACIÓN EN EDUCACIÓN Y CAMPO DE LA FORMACIÓN DE EDUCADORES: DIÁLOGOS CON MARLI ANDRÉ}

RESUMEN: El artículo trata cuestiones conceptuales sobre aspectos de la delimitación del campo de la investigación científica, así como cuestiones relacionadas con la investigación en la formación de educadores. Estos temas fueron objeto de intensos intercambios con Marli André durante nuestras experiencias académicas y asociaciones de investigación. Se discuten aspectos relacionados con la validez y consistencia de la producción científica, discutiendo la variedad de posibilidades que surgen del uso de métodos cualitativos en la investigación en educación y en la formación del profesorado, así como las inquietudes sociales y educativas que plantea un enfoque investigador-investigador más cercano. , investigador-contexto.

PALABRAS-CLAVE: Investigación en educación; Investigación cualitativa; campo de investigación; ética 


\section{Introdução}

Neste texto serão abordadas questões conceituais sobre delimitação de campo de investigação científica e questões relativas à pesquisa em formação de educadores. São questões conversadas muitas vezes com Marli André em nossas parcerias em pesquisas e nas discussões acadêmicas que mantínhamos. Marli, professora, pesquisadora, autora, que deixou obras de referência nesses temas e formou tantos professores e pesquisadores. Compartilhar com Marli de vivências acadêmicas diversas significou problematizar, buscar referências, estudar e criar saídas para impasses. Meu trabalho em parceria com Marli André encorpou-se quando passamos a compartilhar, no curso de Doutorado em Educação: Psicologia da Educação na PUC-SP, duas disciplinas formativas voltadas às questões de metodologia da pesquisa. Eu trabalhava no primeiro semestre com os aspectos ligados aos fundamentos lógico-epistemológicos da pesquisa em Ciências Humanas e Educação, e ela, na continuidade no segundo semestre, entrava com os aspectos metodológicos e os meios para a investigação científica. Nossa ligação acadêmica se aprofundou ainda mais porque ambas tínhamos o campo da formação de professores como foco de nossas próprias pesquisas. Não foram poucas nossas conversas, discussões e trocas, o que acabou redundando no compartilhamento da construção e realização de projetos de pesquisa na Fundação Carlos Chagas e minha integração ao seu Núcleo de Pesquisa em Formação de Professores na PUC-SP, no qual permaneci mesmo após minha saída da universidade. Nesse Núcleo as discussões de projetos foi intensa, variando seus participantes no tempo, no qual, a agregação de novos colegas (doutorandos ou pós-doutorandos) movimentava as problematizações e estudos diversos.

\section{Campos de pesquisa científica}

Preocupadas com a questão da validade das pesquisas sobre a formação de professores questionávamos se esse conhecimento se caracterizaria de fato como um campo de estudos científicos, com suas especificidades, na grande área da pesquisa educacional. Algumas discussões tivemos sobre se o conhecimento produzido nesse tema sustentava e sustentaria a construção de conceitos e a elaboração de hipóteses, fundamentando a construção de objetos próprios de investigação, orientando tanto perspectivas teórico-epistêmicas como a escolha dos meios de aproximação de realidades, bem como a crítica do processo investigativo, entre outros aspectos. Nossos estudos sobre a produção das pesquisas em educação e em formação de professores, mostrou sinalizadores de um campo, um espaço de produção de relações conceituais e inferências, como sínteses interpretativas de problemas reais em sintonia com pressupostos assumidos. Com objeto próprio, embora construído em diferentes perspectivas e variadas conotações, o conjunto de estudos sobre formação de professores se mostrava, sim, configurando um campo científico, em parâmetros específicos. Porém, diante da variedade de abordagens encontradas nas pesquisas sobre formação de professores, aparecia a dúvida se havia um domínio específico desse campo de investigação ou um domínio que assegurasse de alguma forma uma certa unidade (fatos, teorias, postulados, etc) permitindo-lhe, face a outros campos, conservar uma certa especificidade, tendo com isso, a possibilidade de integrar a multiplicidade de olhares que um campo de pesquisa pode criar. Isto me levou a discutir em vários textos que não se tratava de assumir uma unidade de campo científico como homogeneidade, mas uma unidade de propósitos com clareza de abrangência e de estruturas conceituais. Ou seja, um campo de estudos legitimado pela comunidade científica com identidade pensada como uma topologia de metamorfoses, identidade e legitimidade construídas. Um campo em que, um processo transacional de cooperação conflituosa e contraposições frutíferas se processam. (SCHURMANS, 1998). Embora campo que se mostra heterogêneo, e caudatário das perspectivas mais amplas que se evidenciam na área da pesquisa em educação amplamente considerada, seu objeto é distinto, demandando e orientando abordagens com um tipo particular de encontro com a empiria, de atitudes e valores, de orientações teóricas, revelando características próprias de levantamento de dados, fatos, ocorrências, percepções, representações, etc. 
Embora reconhecendo que nem todos os estudos nesse campo correspondam às características necessárias para serem tomados como válidos, um conjunto significativo deles enuncia a criação de um corpo de conhecimentos consistentes, com plausibilidade demonstrável, fundamentada em procedimentos de busca criteriosos e sistemáticos. Um conhecimento que vai além da aparência de fatos, narrativas, evidências, desvendando processos, trazendo compreensões ou explicações consistentes relativas a uma problemática segundo algum referencial claro, tomado como ponto de partida ou construído a partir das análises. Nessa perspectiva assume-se a ideia de que um campo de conhecimento se constrói e reconstrói na história, um campo sempre está em mutação, o qual não se pode analisar numa perspectiva unicista, na perspectiva de ajuste a um só paradigma. Seu estatuto epistemológico não comporta uma só lógica, uma única forma de interpretar fatos, narrativas, imagens, etc. Seus processos de trabalho, com diferentes formas de aproximação de seu objeto, constroem-se e reconstroem-se no tempo, como também nos vários contextos sócio-históricos culturais onde os seus procedimentos de investigação são gerados ou empregados. Nessa visão, várias possibilidades se criam, seja as da multiplicidade de enfoques sem questões de padrões únicos de referência, seja as dos processos de constituição dos conhecimentos humanos em um fluxo histórico contínuo, mas que tem rupturas e contradições, seja nas perspectivas da ideia de complexidade ou das redes de significação. A não identificação de um paradigma hegemônico como definição para um campo científico, ou a convivência de formas paradigmáticas diversas para legitimar conhecimentos, ou a pouca preocupação com adesão ou construção de consensos em estruturas de conhecimento, parecem ser aspectos que caracterizam a pesquisa na área da educação e em formação de professores. Essa uma visão que rompe com a positividade que dominou por muito tempo as perspectivas sobre a constituição de áreas ou campos de conhecimento. Não se trata aqui de desestruturação ou desconstruções irrelevantes, mas, sim, de construção ou reconstrução de referentes e formas de aproximação do real que sinalizem sentidos e direções para os conhecimentos visados. A ideia de composição entre epistemologias faz-se presente. $\mathrm{Na}$ esteira de Boaventura de Souza Santos, dentre outros, podemos falar do emprego na pesquisa de uma atitude de "errância epistemológica", de percursos epistemológicos diversos ante fatos intrincados e dinâmicos. Esse autor nos fala da pluralidade epistemológica do mundo, o que nos reporta à necessidade de olhares de natureza variada para compreendê-lo. (SANTOS, 2000). A ciência, na modernidade, gerou um cientificismo estreito nos limites de visões únicas, o que criou um certo obscurecimento em relação a epistemologias (OLIVEIRA, 2005), e criou, também, "a necessidade de superação do cientificismo moderno e dos epistemicídios perpetrados em seu nome..." (OLIVEIRA E ALVES, 2006, p. 80)

\section{Questões sobre Pesquisas Qualitativas}

Voltando aos diálogos mais diretos com Marli, muitos desafios teóricos e metodológicos enfrentamos em estudos de larga escala e nas pesquisas de campo e estudos de caso. Desafios que compartilhamos com nossos outros parceiros de pesquisa. Trabalhar com questões como políticas e programas de formação de professores em seus desdobramentos nas realidades, planejar e realizar estudos de campo para estudar em estados e municípios de várias regiões do país as propostas para a docência, construir referentes e meios de análise qualitativa para dezenas de milhares de respostas abertas a questionário, para melhor compreender o papel indutor do Pibid e seus significados junto aos diferentes envolvidos nesse programa, analisar no vasto arsenal de produções teóricas concepções ligadas à formação de professores para a educação básica para desvelar aspectos relevantes, garimpar experiências inovadoras na formação inicial e continuada de professores, são exemplos, entre outros, das trilhas percorridas em busca de conhecimentos relativos a diferentes problemáticas concernentes ao exercício da docência na educação básica. Essas questões envolveram lidar tanto com metodologias qualitativas e as de tratamento de documentos, como com metodologias quantitativas, estas também merecendo busca de soluções para que os dados trouxessem possibilidades de 
inferências bem fundadas. Colocar em ação os procedimentos de pesquisa pensados não é mera reprodução do pensado uma vez que relações comunicativas e suas conotações se fazem presentes nos atos de busca, além da possível intercorrência de situações inesperadas durante o processo de realização da pesquisa. Por essa razão é que lembro, ressaltando que método é o percurso de um caminho, um caminhar por algumas veredas: "Método não é algo abstrato. Método é ato vivo, concreto, que se revela nas nossas ações, na nossa organização e no desenvolvimento do trabalho de pesquisa, na maneira como olhamos as coisas do mundo." (GATTI, 1999, p. 63)

Escrevemos juntas artigo sobre a relevância dos métodos qualitativos em educação no Brasil (GATTI, ANDRÉ, 2010) onde lembramos que eles contribuíram significativamente para ampliar e diversificar os conhecimentos na área da educação, e, completo, consequentemente para os conhecimentos voltados à docência. Na maioria das vezes, com foco mais delimitado, esses métodos permitem aproximação mais profunda em relação às formações, aos processos culturais, aos de aprendizagens, adentrando em questões do cotidiano escolar, explorando situações diversas. Com isso, abriu-se mais espaço no universo epistemológico dos debates dos fatos educacionais, ampliando o compromisso com as realidades socioeducacionais e levantando questões de equidade educacional e ética pedagógica e social e ética nas pesquisas. Eles propiciam uma maior aproximação entre pesquisadores e participantes do estudo, e a uma maior penetração nas micro realidades sociais e educacionais. Porém, não deixamos de apontar no texto que, pela leitura de inúmeras pesquisas, relatadas em teses de doutorado ou artigos, encontram-se casos de uma certa licença ou descuidos no emprego desses métodos. Eles são abertos e flexíveis, permitindo ajustes a situações, eventualidades e contextos, mas, a garantia de consistência em processos de investigação científica não pode ser deixada de lado. Decisões metodológicas, nas propostas e projetos, e durante o processo de realização do estudo, precisam ser bem fundamentadas e realizadas para garantir credibilidade aos dados, às análises e interpretações. Os cuidados com a aproximação no campo, nas realidades sociais e educacionais, são aspectos essenciais à validação das análises e inferências.

Vou adentrar aqui um pouco nessa seara das metodologias qualitativas uma vez que as produções no âmbito da pesquisa em formação de professores situam-se nessa vertente. Coloco inicialmente que esses métodos, por sua proposta que envolve, na maior parte dos casos, proximidade e relações entre pesquisador-participantes, pesquisador-contextos, são exigentes quanto à ética de conduta e quanto à garantia de que se circunscreva de modo claro e consistente seu âmbito de significação.

Já dispomos de um acervo de conhecimentos relativos a procedimentos de aproximação do campo de pesquisa pelo caminho que denominamos de qualitativo, procedimentos que devem ser cuidadosamente considerados, uma vez que se originaram de experiências e vivências de trabalho com esses métodos e das reflexões sobre suas condições em garantir conhecimentos válidos. Não se pode banalizar procedimentos que merecem certo grau de rigor, o que não quer dizer petrificação de regras de ação em pesquisas. Muitos formatos vêm sendo gestados nessa seara diversificando possibilidades de acesso a fatos, pessoas, depoimentos orais e escritos, opiniões, representações, compreensões, linguagens e expressões, movimentos sociais, culturais, corporais, na direção de possibilitar elaborações compreensivas que trazem em seu bojo novos conhecimentos, assim alimentando o corpo de saberes na área da educação e, particularmente, no campo da formação de professores.

No decorrer histórico da utilização de metodologias qualitativas alguns impasses surgiram, por exemplo, de início, em um mundo acadêmico habituado às positivações e a um racionalismo estrito, o próprio reconhecimento dessas metodologias como científicas. Ou, a questão da pertinência de uso na área da educação 
de metodologias e procedimentos de pesquisa criados em outras áreas e campos de conhecimento com objetos e focos de estudo tão diferentes. Ambas essas questões hoje parecem superadas.

Com o envolvimento cada vez maior de pesquisadores com as problemáticas sociais e educacionais, o envolvimento com a necessidade de superação de desigualdades inaceitáveis, e o desejo de buscar pela pesquisa alternativas para a melhoria das condições de vida e trabalho, pesquisadores-educadores engajaram-se na busca por metodologias mais condizentes com possibilidades de construção de transformações sociais. Historicamente foram surgindo abordagens metodológicas qualitativas visando responder a posições filosófico-políticas específicas: a pesquisa ação, a pesquisa intervenção, pesquisa participante, pesquisa-intervenção-participativa, pesquisa colaborativa e outras denominações. Tomam corpo na área da educação e no campo das pesquisas com a docência, perspectivas da etnografia, da etnometodologia, da etnopesquisa crítica, etnopesquisa formação, etnopesquisa implicada, pesquisa engajada. Metodologias em movimento, dinamizando variadas formas do conhecer.

Um exemplo de criação de possibilidades metodológicas na vertente qualitativa, foi quando surgiram problemas a investigar que colocavam o pesquisador diante de um aparente vasto universo de fontes possíveis, para a construção de um conjunto viável de pesquisados (de alguma forma representativos de uma dada situação), porém, evidenciava-se grande dificuldade com informações esparsamente encontradas, dificuldades com a obtenção direta de dados, deixando a desejar quanto aos fundamentos para o como decidir, por exemplo, quais contatos, por onde começar, etc. $\mathrm{O}$ acesso às fontes mostrava-se dificultado por razões como, o não se saber onde a informação buscada de fato está, ou porque as fontes sondadas se mostram frágeis e incompletas. Um problema inédito, surgido em circunstâncias específicas, pode trazer essa dificuldade de selecionar fontes com critérios básicos justificáveis. Uma proposta experimentada, e hoje, aceita - quando bem conduzida e explicada -, é a chamada "garimpagem". A garimpagem, na pesquisa humano-social, demanda procedimentos flexíveis na coleta de informações, com variações quanto aos meios de se aproximar das realidades buscadas, admitindo mudança ou agregação de focos de busca no percurso, experimentando-se caminhos variados em comprometimento com realidades. Essa é uma abordagem já reconhecida no âmbito das pesquisas qualitativas. (PASSOS et al., 2015). A garimpagem é um tipo de estudo que acolhe os dados, ao invés de escolhê-los, uma forma de pesquisar por aproximações sucessivas, que cria "a possibilidade de pensar e escrever, de compor uma pesquisa com os heterogêneos recolhidos a partir dos mais diversos lugares", e que é: "Não mais a aplicação de passos prévios, portanto, mas a invenção de pistas, um compromisso com as realidades a serem cartografadas, com as intervenções." (NEUSCHARANK et al., 2019, p.4). Surge aqui o conceito da construção de uma cartografia como forma associada à garimpagem. Esses procedimentos investigativos têm suas fontes de inspiração em Gilles Deleuze e Félix Guatari, que em suas produções privilegiam processos de aproximação de realidades e sua imagética e onde as diferenças são pensadas, e a ideia de construção de uma cartografia, de um mapa significante, por garimpagem se mostra como a construção de um rizoma que evoca significados de ações e expressões, produzindo "territórios" com uma "rede" de sentidos. (DELEUZE; GUATARI,1995)

Nessa vertente de construção de conhecimentos, lida-se com o possível, o que emerge a partir de informações que aproximam de personagens, documentos, imagens, etc., em um caminho tecido por sinalizações diversas, fontes variadas, sejam pessoas, outros pesquisadores, colegas de trabalho, grupos relevantes, documentos, um artigo, ou tese, uma notícia, obtendo-se no trajeto, depoimentos, escritos, falas e gestos, de relevância para as questões que preocupam e guiam a rota dos pesquisadores. Parte-se de ganchos iniciais, que se abrem em várias rotas, que abrem caminho para a obtenção de elementos relacionados ao problema que se pretende analisar, muitas vezes, aparentemente desconectados e díspares, mas que propiciam delinear confrontações, relações e sentidos. 
Outra lógica de abordagem do "real", em que se admite, e se mostra, que o surgido valida interpretações dentro de dadas circunstâncias. A garimpagem abre caminho para outras problematizações e outras abordagens, sem deixar de oferecer conhecimento com certo grau de consistência e significação. Essa abordagem foi utilizada em uma parte do último trabalho de pesquisa que compartilhamos com Marli André, Elba Barretto e Patrícia Albieri de Almeida (GATTI et al., 2019, caps.VI e VII). A discussão aqui apresentada não está lá, mas, foi a inspiração para as análises produzidas e foi objeto de conversas minhas com Marli. Ela tinha a preocupação de se assegurar da pertinência das análises e sínteses propostas como sinalizadoras e inspiradoras.

Para a pesquisa em educação e, particularmente as voltadas à docência, sobretudo quando adentramos na pesquisa pelo ângulo da busca de compreensão das relações vivenciadas, sejam entre pares, com as hierarquias, as relações pedagógicas, a abordagem pela garimpagem, associada à ideia de uma cartografia pensada como um mapa de relevâncias, abre um leque de possibilidades particularmente na atenção do que emerge como diferente, diverso e não só o comum, o que resulta bem, ou seja quando se pretende estar atento aos signos do heterogêneo, diferentemente do que é usual: a busca do comum, do positivo, do produtivo, do que "dá certo", deixando de lado as "inconveniências", os problemas, os percalços, os insucessos eventuais. Essa metodologia, que agrega dois conceitos, garimpar e cartografar, aos quais se agrega o de agenciar, em que agenciamento se identifica com movimentos de ligação, combinação, recombinação, alterações, em contextos, no fluxo de trocas de muitos tipos, trocas que são múltiplas e variadas. (DELEUZE; GUATARI, 1997, p. 31). Encontramos dessa perspectiva, interpretações e adaptações de autores diversos, como Eduardo Passos, Virgínia Kastrup e Liliana Escócia (PASSOS et al., 2015), entre outros, que têm no Brasil utilizado a garimpagem ou cartografia-garimpagem como método de pesquisa. Esses movimentos sinalizam para uma nova forma de abordar estudos sobre a docência - esta concebida sob o ângulo de um "Encontro". Uma situação vivida com. Com vários "cons", inclusive os pesquisadores que se inserem em processo de busca de compreensões em coletivos escolares, seja na educação básica ou na superior, dando vida e significações aos movimentos da docência, em suas possíveis e variadas nuances. Nessa abordagem: "Os pesquisadores fizeram e (fazem) parte desta produção, construindo-se junto à pesquisa. Eles não sabem, de antemão, quais serão os encontros que irão ter e como esses mesmos encontros poderão lhes afetar. De certa forma, estão disponíveis aos acasos que os seus campos lhes oferecem, a imprevisibilidade que se fará no decorrer dos caminhos." (NEUSCHARANK et al., 2019, p.6).

Observamos que a ideia de pesquisa como formação está aí contida, também. Este foi outro tema que ocupou Marli André: a pesquisa que forma, a formação pela pesquisa. Não ficou nesse tema em discussões genéricas preocupada como sempre esteve com o papel da pesquisa na formação inicial e continuada de professores, e no desenvolvimento da vida profissional de educadores em geral. Por isso, pesquisou tema, que problematizava e distinguia aspectos relativos às possibilidades de desenvolvimento de um professor-pesquisador. Assim, em pesquisa e artigo que publicou com Marly Krüger de Pesce (PESCE; ANDRÉ, 2012), trata da questão com base em dados. a qual tem grande atualidade, vez que a questão do conceito de professor-pesquisador e de sua prática ainda suscita controvérsias no contexto do exercício cotidiano da docência. No artigo logo acima citado, as autoras apresentam resultados obtidos em uma pesquisa que teve como objetivo compreender como professores formadores têm desenvolvido a formação do professor-pesquisador. As análises apontaram que esses formadores têm diferentes concepções do que é pesquisa, evidenciando uma variedade de perspectivas, nem sempre conciliáveis. Há o reconhecimento da pesquisa para a atualização dos conteúdos e formas com que o professor trabalha, bem como para a melhoria da prática docente. Concluem das análises, as autoras, que os dados sugerem "que a formação do professor pesquisador é uma proposta em construção, exigindo dos professores formadores a mesma competência delineada para o perfil do professor da educação básica: uma postura investigativa, que, ao conhecer a realidade, possa agir de forma consciente e crítica para transformá-la e se transformar." (PESCE; ANDRÉ, 2012, p. 49) 
Em tudo o que aqui se colocou há um pano de fundo necessário: a formação cultural ampla necessária ao pesquisador que escolhe trabalhar com métodos qualitativos em suas investigações. Cultura geral e cultura interdisciplinar, científica, ambas necessárias à imaginação criativa, interpretativa do pesquisador. Imaginação não como ilusão que encanta, mas imaginação que constrói conhecimentos fundamentados com ilações pertinentes. 


\section{Referências}

DELEUZE, Gilles; GUATTARI, Félix. Mil platôs: capitalismo e esquizofrenia. 1. ed. São Paulo: Editora 34, v.1, 1995.

DELEUZE, G.; GUATTARI, F. Mil platôs: capitalismo e esquizofrenia. 1. ed. São Paulo: Editora 34, v.2, 1997.

GATTI, B. A. Algumas considerações sobre procedimentos metodológicos nas pesquisas educacionais. Eccos Revista Científica, UNINOVE, São Paulo, N. 1, 1999, p.63 - 79.

GATTI, B.A.; ANDRÉ, M. E. D. A. A relevância dos métodos de pesquisa qualitativa em Educação no Brasil. In: WELLER, W.; PFAFF, N. (orgs). Metodologias da Pesquisa Qualitativa em Educação. Petrópolis, R. J: Vozes. p.29-38, 2010.

NEUSCHARANK, A; DALMASO, A. C.; OLIVEIRA, M.O. Agenciamento cartografia-garimpagem: um modo de produzir pesquisa em educação. Educação, Porto Alegre, v. 42, n. 1, p. 3-11, jan.-abr. 2019.

OLIVEIRA, I.B. Aprendendo a ler/ver/ouvir as práticas das professoras no cotidiano escolar. In: Seminário Internacional III, Editora D. P \& A, 2005, 1cd-rom.

OLIVEIRA, I.B., ALVES, N. A importância do diálogo entre as múltiplas formas de fazer pesquisa em Educação: sobre as relações possíveis entre práticas e teorias. Educação \& Linguagem, UMESP, v.9, n.14, São Bernardo do Campo, 2006, p. 59-89.

PASSOS, E.; KASTRUP, V.; ESCÓSSIA, L. (org.). Pistas do método da cartografia: pesquisa-intervenção e produção de subjetividade. 4. ed., Ed. Sulina, Porto Alegre: 2015.

PESCE, M.K.; ANDRÉ, M.E.D.A. Formação do professor pesquisador na perspectiva do professor formador. Formação Docente: Revista Brasileira de Pesquisa sobre Formação Docente. Belo Horizonte, v. 04, n. 07, jul./dez. 2012, p. 39-50. Disponível em http://formacaodocente.autenticaeditora.com.br Acesso: 04/09/2021.

SANTOS, B.de S. A crítica da razão indolente: contra o desperdício da experiência. Cortez Editora, São Paulo, 2000.

SCHURMANS, M.-N. Les sciences de l'éducation : fantôme, agrégat, prototype ou idéal-type? In : Hofstetter, R.,Schneuwly, B. (ed.) Le pari des sciences de l'éducation. Raisons éducatives, 98 : 1-2, Paris-Bruxelles, De Boeck Université, 1998.

Gatti, B. A., A pesquisa em Educação e o campo da formação de educadores: diálogos com Marli André. Formação Docente - Revista Brasileira de Pesquisa sobre Formação de Professores. Belo Horizonte. Vol. 13, nº 28 (p. 47-56) 31 dez. 2021. ISSN: 2176-4360. DOI https://doi.org/10.31639/rbpfp.v13i28.546 
